\title{
Delivery and communication of severe weather events in Basque Country: the Euskalmet case
}

\author{
Santiago Gaztelumendi ${ }^{1,2}$, Iñaki Orbe ${ }^{1,2}$, Onintze Salazar ${ }^{1,2}$, Ana Lopez ${ }^{3}$, José Antonio Aranda ${ }^{2,3}$, and \\ Pedro Anitua ${ }^{3}$ \\ ${ }^{1}$ Tecnalia, Energy and Environment Division, Meteorology Area, Miñano, Araba, Basque Country, Spain \\ ${ }^{2}$ Basque Meteorology Agency (Euskalmet), Miñano, Araba, Basque Country, Spain \\ ${ }^{3}$ Basque Government, Security Department, Directorate of Emergencies and Meteorology, Vitoria-Gasteiz, \\ Araba, Basque Country, Spain \\ Correspondence to: Santiago Gaztelumendi (santiago.gaztelumendi@tecnalia.com)
}

Received: 14 January 2016 - Revised: 18 April 2016 - Accepted: 25 April 2016 - Published: 10 June 2016

\begin{abstract}
In this work we briefly introduce some aspects about delivery and communication of severe weather events in Basque Country, explaining what is considered severe weather by the Basque Meteorology Agency (Euskalmet) in the context of Basque Country. We include a short description of some products generated for different purposes during such events, presenting different aspects related with delivery and communication processes in the operational context of Euskalmet. We review some real examples on severe weather communication and message dissemination in Basque Country. Finally, some conclusions about our experience are presented.
\end{abstract}

\section{Introduction}

The Basque Meteorology Agency (Euskalmet) is responsible for severe weather forecast for the Basque Country area, among other duties. Information available for a particular adverse event must be communicated properly at different levels, including emergency authorities, media and general public. This is a complex process where we need to ensure that forecasts and other messages are understood by heterogeneous recipients and appropriate action is taken by end-users, and especially by the general population. In 2010 Euskalmet has moved from the Meteorology and Climatology Directorate (Department of Transportation and Public Work) to the Directorate of Emergencies and Meteorology (DEM) in the Security Department merging civil protection, emergencies, meteorology and climatology in the same structure. Different meteorological procedures and communications strategies have been migrated toward a more flexible impact-based approach, mainly focused on final users and civil protection needs.

\section{Severe weather in Basque Country}

In Euskalmet procedures (GV, 2009, 2011, 2014), severe weather events are considered for maritime-coastal impact (Gaztelumendi et al., 2015) and inland when rain, snow, temperature or wind can cause different types of problems (Gaztelumendi et al., 2012).

For rain we consider persistent and/or intense precipitation, where key parameters are accumulated rain in $24 \mathrm{~h}$ and in one hour respectively. Persistent rainfall situations have usually good predictability and result in a general increase in river levels and occasionally flood events in different river basins. On the other hand, intense rains, associated with thunderstorms, are less predictable in detail and can cause less extensive flash-floods.

When snowfall affect any part of territory under $1000 \mathrm{~m}$ potential impact is a threat Snow thickness and altitude are the key factors, but some demographic considerations about affected populations and roads are introduced.

In the case of wind, we consider terrain characteristics, and distinguish exposed and non-exposed zones. The first ones usually include sparsely populated areas in mountains and coastal areas. The rest of the territory (usually populated ar- 
eas in valleys) are considered non-exposed, In this case, key parameter is wind gust.

For temperatures, we consider different thresholds for maximum and minimum temperatures for an ad-hoc territory zonification. Extremely high temperatures where maximum temperatures are very high can lead to different health problems as heat strokes. The persistence of high minimum and maximum temperatures can promote heat waves affecting day and night during consecutive days, causing different health conditions. In the case of extremely low temperatures and frost, problems usually come from ice presence in roads and streets.

In the coastal-maritime case, we consider three different situations. First of all, that promote problems for navigation, taking into account the waves characteristics and the wind behaviour. In the second place, when, due to a combination of waves and tides, impact on coast is expected due to flooding or/and energetic wave push. Finally, we consider a particular mesoscale phenomena that could take place in Cantabric Coastal area, a particular CTD (Coastal Trapped Disturbance) that promotes a sudden wind reversal that can impact on littoral activities (especially in beach users). In this case, key factor is wind gust (see Gaztelumendi et al. (2011) for more details about "Galerna" event).

\section{Severe weather products}

Many different products are made before, during and after a severe weather event, but one of the key products is the warning bulletin. This product answer what?, where? and when? questions and categorize potential impact with three color levels (yellow, orange and red) (GV, 2015; Gaztelumendi et al., 2012). If a severe event may affect the Basque Country area, different products are elaborated, including warnings in different formats for mailing, web, twitter and mass media. In some cases others supporting products are also prepared, as special bulletins for snow, sea conditions, extreme temperatures, floods, etc. During the event, twitter is used in order to translate, in real time, data and information about probable evolution of the event to users (Gaztelumendi et al., 2013). After each orange or red severe weather episode an analysis document is prepared in different formats for internal use and also a version for public dissemination. Especial quality control is done for severe weather episodes (see poster EMS2015-456).

\section{Communication aspects}

All products and data available before, during and after each severe weather episode must be transformed into appropriate information (message) for each user (receiver) and transmitted properly in each case (delivery). There are many aspects to consider in this communication process. In the Euskalmet case communication questions as What?, When?, How?
Who? To whom? Where? are answered in different procedures and protocols (GV, 2015). Here we focus only on some dependencies between transmission process, type of message and receiver characteristics.

Regarding receivers, and from the meteorologist point of view, we can consider technical/experts (Euskalmet and some emergency staff) and non-technical/non-expert people (some civil protection and emergency people, politicians, journalists and general public). Initial Meteorological products must be transformed in different ways into messages, adapting technical aspects to the expected technical expertise of receiver. In any case, simplification and orientation to impact always help in transmission of the key aspects of a particular event.

In relation to the transmission channel, we use mass media (press, radio, television), social networks (mainly Twitter and Youtube), Internet, telephone and personal communication. Severity, temporal horizon to the event, predictability, delivery time information needs, type of information and expected impact are drivers to select the channels to be used.

In relation to the message, the most relevant aspect, from the meteorological part of the communication chain, is to guarantee that the message is not substantially different when it arrives to target than when it was emitted. If the transmission process is direct, we need to explain the situation correctly and in an adequate manner depending on receiver and channel used. If thirds parts are involved (usually journalists), message perturbations are often produced when oral transmission is done and often even if a press release is distributed in advance (Orbe, 2012).

\section{Delivery aspects}

In terms of message delivery, during a severe weather event and associated emergency, it is important to be: first, accurate, honest, accessible, credible, willing and able to correct misinformation and quell rumours, consistent, appropriate, regular and relevant (Hyer and Covello, 2005; Covello and Allen, 1988). Delivery aspects of a particular severe event is usually driven from expected impact.

The Yellow or Warning level is a situation where the risk is low and limited for individuals and specific activities, it is a non-unusual situation (see Fig. 1). In this case, delivery will be, unless expressly requested by the media, mainly by direct channels, mainly using radio, television, twitter, e-mail and the Web for transmitting different products and soft messages (see Fig. 2).

The Orange or Alert level is a situation of medium dangerousness affecting certain sectors of population, is an unusual situation (see Fig. 1). In this case messages are transmitted both directly and indirectly through the media. In addition to the standard products, press releases are prepared and the presence of technical personnel in meteorology or emergencies in the media (newspapers, radio and television) 


\begin{tabular}{|c|c|c|c|c|c|}
\hline Level & Weather & $\begin{array}{l}\text { Key mesaage to } \\
\text { general public }\end{array}$ & Risk & Damages & Frequency \\
\hline & $\begin{array}{c}\text { Not } \\
\text { dangerous }\end{array}$ & $\begin{array}{l}\text { No particular awareness is } \\
\text { required }\end{array}$ & No risk & No damages. & Usually \\
\hline Warning & $\begin{array}{l}\text { Potentially } \\
\text { dangerous }\end{array}$ & $\begin{array}{l}\text { Keep informed especially } \\
\text { depending on your activity }\end{array}$ & $\begin{array}{l}\text { No risk for general population } \\
\text { but do not take any avoidable } \\
\text { risk depending on your activity }\end{array}$ & $\begin{array}{c}\text { Some disturbances } \\
\text { and very } \\
\text { few/occasional } \\
\text { damages } \\
\end{array}$ & $\begin{array}{l}\text { Many times a year } \\
\text { /not unusual }\end{array}$ \\
\hline Alert & Dangerous & $\begin{array}{l}\text { Be very vigilant and keep } \\
\text { regularly informed about the } \\
\text { detailed expected } \\
\text { meteorological conditions }\end{array}$ & $\begin{array}{c}\text { Moderate/high risk. Follow any } \\
\text { advice given by authorities. Be } \\
\text { aware of the risks that might } \\
\text { be unavoidable }\end{array}$ & $\begin{array}{l}\text { Moderate and/or } \\
\text { localized damages }\end{array}$ & $\begin{array}{c}\text { Very few times a } \\
\text { year }\end{array}$ \\
\hline Alarm & $\begin{array}{c}\text { Very } \\
\text { dangerous }\end{array}$ & $\begin{array}{l}\text { Keep frequently informed } \\
\text { about detailed expected } \\
\text { meteorological conditions } \\
\text { and risks }\end{array}$ & $\begin{array}{l}\text { Very high risk. Follow orders } \\
\text { and any advice given by } \\
\text { authorities under all } \\
\text { circumstances, be prepared for } \\
\text { extraordinary measures }\end{array}$ & $\begin{array}{l}\text { Major and/or } \\
\text { generalized } \\
\text { damages } \\
\text {,casualties are } \\
\text { possible }\end{array}$ & $\begin{array}{l}\text { One time in a few } \\
\text { years }\end{array}$ \\
\hline
\end{tabular}

Figure 1. General considerations depending on warning level.

is favoured, with limited presence of non-technical government managers (see Figs. 1 and 2).

The Red or Alarm level is an exceptional situation with a high dangerousness for large part of the population (see Fig. 1). In this case delivering aspects are quite similar to those in orange level, however increased media awareness and exposure will occur as relevant government authorities issue specific protocols and emergency plans (Fig. 2).

\section{Case examples}

Here we present some case examples. The first case highlights the perverse combination of sensationalised news in relation to severe weather, the ease with which false news can be amplified when you have the right ingredients, but also how you can use the same weapons to remedy the situation. The second example shows the benefits of the direct transmission of information in real time through Twitter. In the third case we show how even the official information transmitted in a press release may be distorted by a journalist, resulting in a misleading or incorrect message being given to the newspaper readers.

\subsection{Action against hoaxes}

On 29 January 2015, some Basque media echoed a hoax that warned of the arrival of a historic snowfall to Vitoria-Gasteiz city. The rumour stemmed from Whatsapp and rapidly spread to other social networks, and consisted of an anonymous piece of information about a council government worker being heard quoting an expert meteorologist that the snow episode for the forthcoming week-end could reach $145 \mathrm{~cm}$ on the Basque capital city (never seen before) and that it should be advisable to stock up on food. The DEM issued a message using social media Euskalmet and 112_SOSDeiak channels to refute the hoax and likewise transferred to the press the real forecast and most probable situation. The enormous impact of this hoax (anonymous, of course) also had immediate amplification in other social networks finally reaching the

\begin{tabular}{|c|c|c|c|c|}
\hline Level & & Warning & Alert & Alarm \\
\hline Situation & Normal & Normal & $\begin{array}{l}\text { Not } \\
\text { Normal }\end{array}$ & Exceptiona \\
\hline Dangerousness & $\begin{array}{l}\text { Nearly } \\
\text { none }\end{array}$ & Low & Medium & High \\
\hline $\begin{array}{c}\text { Web-Bulletin and extended information to general } \\
\text { public }\end{array}$ & No & Yes & Yes & Yes \\
\hline $\begin{array}{l}\text { Email - Bulletin and supporting information to public } \\
\text { and private agents affected by particular event }\end{array}$ & No & Yes & Yes & Yes \\
\hline $\begin{array}{c}\text { Twitter (@Euskalmet y @112_SOSDeiak) - Short } \\
\text { messages to users }\end{array}$ & No & Yes & Yes & Yes \\
\hline SMS - Short messages to public and private agents & No & No & Yes & Yes \\
\hline Mass media - Press release & No & Depends & Yes & Yes \\
\hline $\begin{array}{l}\text { Different specifics protocols and emergencies plan } \\
\text { activation }\end{array}$ & No & No & Depends & Yes \\
\hline $\begin{array}{l}\text { Distribute actuation recommendations and self- } \\
\text { protection measures specific for each event type }\end{array}$ & No & Depends & Yes & Yes \\
\hline
\end{tabular}

Figure 2. Operational procedures for severe weather events.

traditional Basque press. After the official denial (before the episode), mass media focused on the risks of mis-information through social networks.

\subsection{Real time surveillance and transmission to users}

Where good real time data is available, Twitter is the perfect tool to deliver real time messages. At Euskalmet we have 100 AWS giving data each $10 \mathrm{~min}$, dual polar radar, and light discharge systems, etc. Using twitter is effective for us, as we have qualified staff working $365 / 24 \mathrm{~h}$ and we know that mobile phone usage is extensively used by the general public.

As an example of this common practice in Euskalmet, we can mention the real-time monitoring performed during severe weather events coinciding with massive public events or during flash floods. For example a concert of Bruce Springsteen was affected by heavy showers, and more than twelve tweets were issued with timely information about shower windows, radar information and short-term forecast. In flash flood events Twitter is a great ally, plenty of messages were sent with timely information of event evolution, including forecasts, radar images, precipitation and river level records (more details in Gaztelumendi et al., 2013, 2015). 


\subsection{Misinterpreting an official press release}

One of the most graphic examples of the perverse misinterpretation of official messages in the Basque Country could be the case of "Jolle" and its effects in Basque coast in January 2013. The official press release issued by the Department of Security of the Basque Government (based on Euskalmet information) talked about an "exceptional explosive cyclogenesis" taking place in the Atlantic Ocean far away from Basque coast with the unique local impact of waves greater than $5 \mathrm{~m}$ (just the orange level threshold). Some newspapers interpreted the press release sensationally, and transmitted to readers that a historical and exceptional cyclogenesis would affect Basque Country.

\section{Conclusions}

Communication is not just an activity that is planned, delivered, and checked off as done. It is instead a complex process of reaching mutual understanding, during which participants (communicator and audience) exchange, create, and share thoughts, opinions, and information.

Effective communication is a two-way activity.

A good strategy for message delivery to the general public must include: traditional mass media (where general public passively receive information) and new social media (where we can deliver key messages and have some feedback and direct contact with end-users).

Word of mouth, supported with some documentation, including data, maps and some comparison with similar episodes, is still the most important source of delivering severe weather information to emergency, civil protection staff and others agents directly involved in crisis management.

Careful selection of the medium and the message favours the correct transmission but does not guarantee the absence of misinterpretation. The occurrence of misinterpretations will be much lower if the message is clear, concrete and concise and the number of intermediaries is minimal and without spurious interests. There are a host of organizational, legal and professional constraints that affect the ability of journalists to become informed and to cover a story effectively. Journalists act as message providers and audience members, and use their own value systems, constraints, experience and expectation to construct a universe of its own, a "media reality" that does not necessarily mirror actual reality.

Deciding when to go public is a difficult and relevant task in severe weather emergencies. At what point does sufficient credible information exist to warn the public? There is no direct answer for that, but our experience shows some key factors: weather forecast predictability, level, type of risk and size of affected population, message adapted over time, better control of accuracy if you are the first one to communicate.
It is important to promote actions in order to guarantee that specific users (even the general public) have enough culture of awareness and self-protection and a general understanding of emergencies and risk associated with local severe weather events. Communications have to convince people that a given event and associated emergency is serious enough to warrant changing behaviour.

We need to explain briefly and clearly the level and reason for the warning including basic details and to describe explicit risk-reducing and self-protection actions. This is a task that needs to be done hand in hand by weather and emergency specialists with a high degree of communication skills.

Acknowledgements. The authors would like to thank the Emergencies and Meteorology Directorate - Security Department - Basque Government for public provision of data and operational service financial support. We also would like to thank all our colleagues from Euskalmet for their daily effort in promoting valuable services for the Basque community.

Edited by: D. Cotgrove

Reviewed by: G. Fleming and one anonymous referee

\section{References}

Covello, V. and Allen, F.: Seven cardinal rules of risk communication, US EPA, Office of Policy Analysis, Washington, D.C., 1988.

Gaztelumendi, S., Egaña, J., Ruiz, M., Pierna, D., Otxoa De Alda, K., and Gelpi, I. R.: An analysis of Cantabric coastal trapped disturbances, 6th EuroGOOS Conference 2011, 4-6 October 2011, Sopot, Poland, 146-151, 2011.

Gaztelumendi, S., Egaña, J., Otxoa-de-Alda, K., Hernandez, R., Aranda, J., and Anitua, P.: An overview of a regional meteorology warning system, Adv. Sci. Res., 8, 157-166, doi:10.5194/asr-8-157-2012, 2012.

Gaztelumendi, S., Orbe, I., Lopez, A., Aranda, J. A., and Anitua, P.: Social media and high impact weather communication in Basque Meteorology Agency, 13th EMS/11th ECAM, 9-13 September 2013, Reading, UK, 2013.

Gaztelumendi, S., Martija, M., Principe, O., and Palacio, V.: An overview of the use of Twitter in National Weather Services, Adv. Sci. Res., 12, 141-145, doi:10.5194/asr-12-141-2015, 2015.

GV: Plan de predicción y vigilancia de fenómenos meteorológicos adversos, internal documentation from Basque Government, 2009, 2011, 2014.

Hyer, R. N. and Covello, V.: Effective Media Communication during Public Health Emergencies: A WHO Handbook, WHO/CDS/2005.31, WHO, Geneva, 2005.

Orbe, I.: Emergencias y medios de comunicación, Publicación de academia vasca de policía y emergencias, Arkaute-Akademia, Vitoria-Gasteiz, Basque Contry, 2012. 